\section{"Isso não é Tumblr": posturas críticas de internautas sobre um vídeo-tutorial no YouTube}

"This is not Tumblr": critical postures of internet users about a tutorial video on YouTube

Adson Luan Duarte Vilasboas SEBA (UNEMAT) adson.seba@unemat.br

Barbara Cristina GALLARDO (UNEMAT) barbarag@unemat.br

Recebido em: 02 de fev. de 2021. Aceito em: 23 de set. de 2021.

\title{
00000000000
}

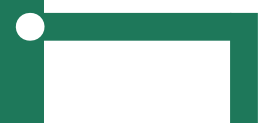

SEBA, Adson Luan Duarte Vilasboas; GALLARDO, Barbara Cristina. "Isso não é Tumblr": posturas críticas de internautas sobre um vídeo-tutorial no YouTube. Entrepalavras, Fortaleza, V. 11, n. 3 , e2313, p. 335-355, set.dez./2021. DOI: 10.22168/2237-632132313.

Resumo: O posicionamento dos usuários por meio da língua(gem) nos espaços on-line é um ato constitutivo das redes sociais e tem sido tema de investigação no campo da linguagem, devido às pistas que sinalizam o funcionamento da sociedade contemporânea. Deste modo, o presente artigo tem o objetivo de investigar o posicionamento de uma produsuária e dos visualizadores de seu vídeo no YouTube que ensina a criar fotos Tumblr, bem como os efeitos de sentido produzidos por este vídeo. Por meio de observação participante, característica da etnografia virtual (HINE, 2000), realizamos uma pesquisa de natureza qualitativa e exploratória. A base teórica está fundamentada em pesquisas que discorrem sobre práticas sociais e de linguagem nos espaços on-line, dentre elas, as de Barton e Lee (2015), boyd (2014) e Coscarelli (2016); e sobre a teoria do posicionamento, a partir de Davies e Harré (1990). A análise dos dados indicou uma tensão entre posicionamentos vigilantes de uma norma versus posicionamentos que reformularam os sentidos impressos no vídeo e fotos postados no YouTube, instruindo usos para o Tumblr. Os resultados apontam que a ideia de liberdade no meio on- 
V. $11(3)$ $335-355$ set-dez 2021

line enfrenta resistência, condicionada a prescrições, mas, ao mesmo tempo, oferece caminhos alternativos para a representação do eu nos espaços digitais.

Palavras-chave: Linguagem. Identidade. Estilo Tumblr. YouTube.

Abstract: The positioning of users through language in on-line spaces is a constitutive act of social networks and has been the subject of investigation in the field of language, due to the clues they offer to understand contemporary society. Thus, this article aims to investigate the positioning of a video producer and some viewers of a YouTube video that teaches how to create Tumblr photos as well as the meaning effects produced by this video. Through participant observation, a characteristic of virtual ethnography (HINE, 2000), we conducted a qualitative and exploratory research. The theoretical study is based on works that discuss social and language practices in on-line spaces, among them, Barton and Lee (2015) boyd (2014) and Coscarelli (2016); and on the positioning theory, developed by Davies and Harré (1990). Data analysis indicated a tension between vigilant positions of a norm versus positions that reformulated the meanings of the video and photos posted on YouTube, aiming at instructing uses for Tumblr. The results show that the idea of freedom in on-line contexts faces resistance, conditioned to prescriptions, but, at the same time, offer alternative ways for the representation of the Self in digital spaces.

Keywords: Language. Identity. Tumblr style. YouTube.

\section{Introdução}

Os velozes desdobramentos tecnológicos da era pós-industrial têm propiciado novas formas de interação, principalmente a partir do surgimento da Web 2.0 ${ }^{1}$, uma plataforma que revolucionou o modo de participação e engajamento dos usuários da internet. Essas mudanças na sociedade contemporânea reverberam novas maneiras de significar e produzir sentidos nos espaços on-line, por exemplo, nas plataformas de redes sociais, onde os usuários têm a possibilidade de se construir textualmente (BOYD, 2007). Isso significa que à medida que consomem e produzem informação², os usuários podem (re)organizar, aperfeiçoar e adaptar o seu conteúdo (BRUNS, 2008, p. 21).

Pelo mesmo viés, Coscarelli (2016) pontua que as redes sociais são amplamente utilizadas na sociedade contemporânea, sendo, portanto, parte constitutiva da rotina dos usuários. Nessa perspectiva, boyd (2014) acrescenta que o caráter público dessas redes, constituídas pela interseção entre pessoas, tecnologias e práticas, as caracteriza pela persistência, visibilidade, distribuição e capacidade de busca, capazes de criar audiências invisíveis e flexibilizar o fluxo entre os domínios público e o privado. Essas características geram um impacto nos modos

\footnotetext{
${ }^{1}$ No ano de 2001 (O'REILLY, 2005).

${ }^{2}$ Como produsuários, nos termos de Bruns (2008).
} 
de participação dos usuários, em suas posturas e atitudes on-line, devido ao envolvimento da mídia nos perfis, a partir da noção de audiência (número de seguidores) e de controle (do Estado, de empresas, da família, etc).

A fim de compreender como se dão as manifestações da linguagem em um espaço on-line, este artigo visa discutir a postura dos usuários de uma rede social na publicação de conteúdo e na forma como os pontos de vista são expressos na interação on-line. Fazemos isso, reconhecendo que "a própria estrutura e os recursos de algumas mídias oportunizam o desenvolvimento de postura, instigando a discussão, a expressão de opiniões, a produção e o compartilhamento de conhecimentos" (MARTINS; SANTOS, 2018, p. 143) nas redes sociais virtuais.

Sendo assim, considerando a participação dos usuários nessas redes por meio dos comentários e as questões relacionadas à audiência, controle e seus desdobramentos, registramos, neste artigo, as características da plataforma Tumblr, para, então, analisar: i) o posicionamento de uma YouTuber que produziu um vídeo (no YouTube), com instruções de postagem para a plataforma Tumblr; ii) os posicionamentos de cinco usuários expressos nos comentários desse vídeo, a partir dos efeitos de sentido produzidos pelo estilo Tumblr nas redes sociais.

Partimos do estudo do posicionamento (BARTON; LEE, 2015; DAVIES; HARRÉ, 1990, 1999) da YouTuber ao atravessar dois gêneros digitais (vídeo/vlog e fotos Tumblr) para então explorar os comentários, marcados por repreensão e elogios ao vídeo publicado. Para tanto, levamos em consideração que esses espaços de escrita on-line possibilitam às pessoas o compartilhamento, a avaliação e a produção de opiniões públicas, os quais Barton e Lee (2015) denominam postura, ou seja, um posicionamento acerca daquilo que é visto ou dito. Sob esse prisma, escolhemos uma rede social para desenvolver este estudo, por ser um espaço, em geral, propício à "[...]utilização da escrita para divulgar conhecimentos, postar comentários, fazer reflexões e relatos pessoais, debater com outras pessoas, [...]utilizando-se não só da modalidade de linguagem verbal, como também da linguagem nãoverbal." (MARTINS; SANTOS, 2018, p. 138).

Assim, utilizamos a teoria do posicionamento como fundamentação científica, seguindo os argumentos de Barton e Lee 
V. 11 (3)

$335-355$

set-dez

2021

$(2015)^{3}$ e tendo em vista os pressupostos que deram origem a esta teoria. Elaborada por Davies e Harré (1990; 1999), a teoria do posicionamento é uma teoria multidisciplinar e de corrente pós-estruturalista, concentrada na análise da distribuição de direitos, deveres e obrigações nas interações, a fim de identificar como esses fatores moldam e, ao mesmo tempo, são moldados pelas estruturas sociais. Para isso, os autores propõem o estudo pontual de episódios sociais em que acontecem a negociação de acessos aos direitos e deveres para a realização de ações. Três categorias de ações regem a tomada de posicionamento: a ação que já está em andamento, já aconteceu ou vai acontecer; a que permite ou encoraja alguém a tomar um posicionamento; a que estabelece que alguém é física e/ou emocionalmente apto/a para determinada tomada (HARRÉ; SLOCUM, 2003).

A aplicação da teoria do posicionamento exige uma análise da inter-relação entre essas três categorias que, segundo Harré e Slocum (2003), orientam a percepção das pessoas sobre o que elas têm direito ou não de fazer. No desenvolvimento da teoria, Harré (2012, p. 4) aponta que, em muitos casos, "os direitos e deveres determinam quem pode usar um determinado modo de discurso, por exemplo, emitir ordens, dar notas, relembrar um evento passado".

Nesse sentido, ao investigar o YouTube e o Tumblr enquanto espaços de posicionamento por meio da língua(gem), devemos considerar que tais espacialidades oportunizam a tomada de posturas, uma vez que instigam a discussão, a expressão de opiniões, a produção e o compartilhamento de conhecimentos, através da produção de material e da manifestação, por meio de comentários. Sob esta égide, o YouTube, por exemplo, é:

[...] uma plataforma rica em posturas e atos de tomada de postura. Os vlogueiros podem expressar suas opiniões sobre determinado tópico por meio da fala em seus vídeos; ao mesmo tempo, os espectadores podem avaliar os vídeos, marcandoos como "gostei" ou "não gostei", ou deixando comentários escritos. (BARTON e LEE, 2015, p. 49).

Barton e Lee (2015) analisam a tomada de postura no espaço virtual, a partir das práticas cotidianas dos usuários que, simultaneamente, organizam e seguem um padrão de funcionamento. Os estudos de Harré e colaboradores (dentre eles, HARRÉ; 2012; HARRÉ;

${ }^{3}$ A teoria do posicionamento foi proposta por Davies e Harré (1990). Barton e Lee (2015) sugerem a abordagem empírica desta teoria nos contextos das redes sociais virtuais. 
LANGENHOVE, 1991; LANGENHOVE; HARRÉ, 1999) propõem a análise da negociação de posturas em episódios pontuais de conversas, na observação dos movimentos de tomada de posição/ ato-ação /enredo (LANGENHOVE; HARRÉ, 1999, p. 19), que podem vincular eventos compartilhados culturalmente, do passado, presente e futuro à ação (SLOCUM; LANGENHOVE, 2003, p. 225). Herbel-Eisenmann et al. (2015 apud KAYI-AYDAR, 2019) explicam que o repertório desses eventos pode já existir ou ser inventado no momento da interação.

Dadas essas considerações, alinhamos este estudo à proposta de posicionamento segundo Barton e Lee (2015) sobre as redes sociais enquanto locais profícuos de práticas de língua(gem), como a tomada de posicionamentos, tendo o contexto virtual multimodal como objeto de análise.

\section{Língua(gem) no mundo digital: formas contemporâneas de se expressar}

Partindo de uma visão da língua(gem) como prática situada, consideramos que o seu uso "está mudando à medida que as pessoas participam de atividades on-line." (BARTON; LEE, 2015, p. 14). Ou seja, para esses autores, a combinação de mudanças em diferentes áreas da vida - resultante do uso massivo das tecnologias digitais - contribui para a transformação em nossas práticas e paisagens comunicativas. Isso acontece devido às potencialidades desses recursos, que incitam "mudanças na textualização [...] na forma como as pessoas produzem e leem os textos, considerando seus objetivos, suas expectativas, seus conhecimentos, crenças e valores." (ZACHARIAS, 2016, p. 20).

Nessa perspectiva, podemos citar, por exemplo, a disponibilidade que as redes sociais oferecem para as pessoas comentarem sobre a publicação de outras pessoas, que incentivam à exposição e produção constante de opiniões. Essa prática causa efeito nos que comentam e nos que expõem sua produção. Para uma abordagem de tais efeitos, é preciso que se leve em conta o contexto de situação - o que está acontecendo, o papel assumido pelos participantes e os recursos utilizados e disponíveis na/para a interação (HALLIDAY; MATTHIESSEN, 2004), já que é a inter-relação entre texto e contexto que confere status de prática social à linguagem. Sobre as múltiplas linguagens dos espaços on-line, Dionísio (2006, p. 131) ressalta que representação e imagens são "textos especialmente construídos e que 
V. $11(3)$ $335-355$ set-dez 2021

revelam nossas relações com a sociedade e com o que a sociedade representa". Na mesma linha, boyd (2014, p. 10-11) discorre sobre a importância de se compreender as novas possibilidades sociais que a tecnologia proporciona e o quão desafiadoras elas são para as interações cotidianas. Segundo essa autora, "compreender as possibilidades de uma determinada tecnologia ou espaço é importante porque lança luz sobre o que as pessoas podem aprimorar ou evitar para alcançar seus objetivos" 4 (tradução nossa5).

A partir dessa perspectiva sobre a linguagem on-line, a seguir, apresentamos um breve histórico da origem, objetivos e desdobramentos da plataforma Tumblr, com o intuito de contextualizar a análise do vídeo e comentários selecionados.

\section{Uma leitura do mundo sob as lentes do Tumblr: posicionamentos por meio da linguagem}

A rede social Tumblr ${ }^{6}$ é um espaço inaugurado em 2007 que possibilita a criação de um blog e a publicação de conteúdos em vários formatos e mídias, tais como histórias, fotos, GIFs, programas de TV, links, vídeos, MP3, moda, arte, entre outros.

O site em inglês informa que, nesta plataforma, o usuário "pode se expressar, se descobrir e se conectar com as coisas que ama. É onde os seus interesses se conectam ao seu grupo"7. O site em português traz a seguinte mensagem "nós deixamos a coisa muito, muito fácil para que as pessoas possam criar um blog e publicar o que elas bem entenderem (...) Tudo cabe nos 497 milhões de blogs que compõem o Tumblr" (grifos nossos).

Apesar dessas orientações, o que se observa, a princípio, é a participação de fashionistas ${ }^{8}$ de todo o mundo, cujas postagens popularizaram a plataforma pelas fotos e animações inspiradoras. Boyd (2014) explica que as comunidades de blogs de moda, criadas por adolescentes no Tumblr, vêm surpreendendo a indústria da moda. A partir dessas mídias, a rede social tornou-se uma espécie de referência para as práticas multimodais on-line e off-line dos seus seguidores.

\footnotetext{
4 "Understanding the affordances of a particular technology or space is important because it sheds light on what people can leverage or resist in achieving their goals."

5 Todas as traduções neste artigo foram feitas pelos autores.

${ }^{6}$ https://www.tumblr.com/

7 "Tumblr is a place to express yourself, discover yourself and bond over the stuff you love. It's where your interests connect you with your people."

${ }^{8}$ Um fashionista é uma pessoa que enxerga a moda como uma forma de arte.
} 
Dentre essas referências estão, por exemplo, o estilo de escrita adotado nas postagens, o modo de se vestir, de se fotografar, gravar vídeos, decorar espaços da casa, entre outros, seguindo determinadas regras que passaram a ser conhecidas no universo digital como o estilo Tumblr.

Para discorrer sobre o estilo Tumblr enquanto uma forma de expressão/posicionamento nas redes sociais, apoiamo-nos nas palavras de Barton e Lee (2015), quando dizem que:

O posicionamento tornou-se um ato discursivo fundamental na interação on-line. Ele não se limita a assinalar as opiniões de quem se posiciona pela escolha cuidadosa do vocabulário e outros recursos; algumas pessoas também querem reforçar um senso único do eu, a fim de se destacar numa comunidade mais ampla de pessoas que se posicionam. (BARTON; LEE, 2015, p. 118-119, grifos nossos).

Assim, podemos dizer que o ato de se autoafirmar Tumblr ou tentar sê-lo caracteriza-se como uma tomada de posicionamento, com o intuito de se destacar nas redes sociais, tendo em vista a representação do estilo Tumblr para esses usuários. Em outras palavras, ao aderir o estilo Tumblr, os usuários podem pretender ser prestigiados através de audiência positiva, indicada pelos likes e comentários sobre suas fotos e vídeos. Os símbolos like e dislike incentivam a tomada de posicionamento dos visualizadores. Conforme observam Barton e Lee (2015, p. 12), "a web 2.0 oferece recursos embutidos que convidam as pessoas a expressar suas opiniões publicamente por meio de multimodais". Essas disponibilidades funcionam como uma engrenagem que garante o funcionamento das redes e a estabilidade na exposição dos usuários.

Nessa direção, para dar visibilidade ao funcionamento do estilo Tumblr nas redes sociais, tomamos como exemplo as fotografias, uma vez que fica patente a (re)significação dessas imagens, ao serem acrescidas à plataforma Tumblr. Sobre este aspecto, o fotógrafo profissional William Lima, do site Criadores Lab", afirma que "Fotos Tumblr não são apenas fotos postadas no Tumblr", mas um estilo específico de se fotografar, originário da comunidade de usuários deste site, que explora novos ângulos, com filtros minimalistas, luz natural e muito estilo.

Para dar nitidez a esses funcionamentos, fizemos uma breve pesquisa no Google Imagens. Ao pesquisar o termo fotos, várias imagens aleatórias aparecem como resultado. Entretanto, ao refazer a busca pelos termos Fotos + Tumblr, verificamos um filtro expressivo nos resultados, conforme ilustra a figura a seguir:

${ }_{9}^{9}$ Disponível em https://criadoreslab.com.br/fotos-tumblr-tudo-sobre/ 
V. 11 (3)

$335-355$

set-dez

2021

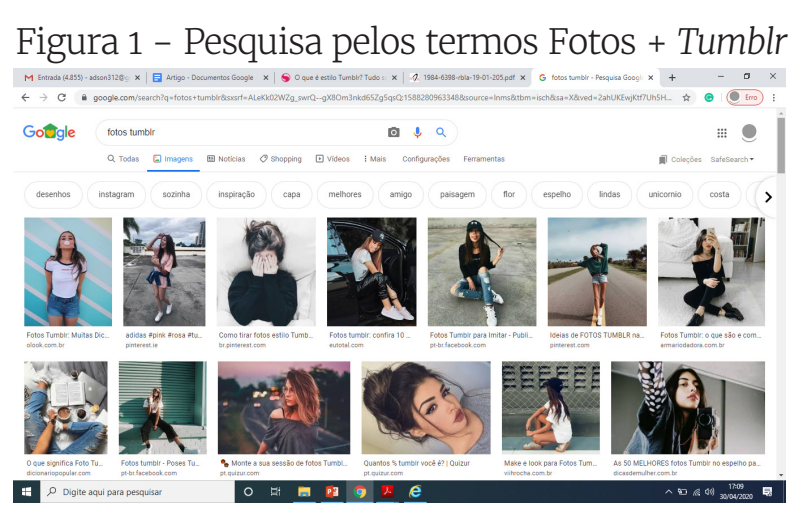

Fonte: Google Imagens (2020).

Observamos que as fotografias, na Figura 1, seguem alguns dos parâmetros estéticos mencionados por Mingo (2017), isto é, o conteúdo das fotografias exibe poses criativas, há cores neutras e destaque nos detalhes minimalistas. Outro aspecto observado diz respeito aos primeiros 55 resultados desta pesquisa, uma vez que exibem apenas imagens de mulheres caucasianas, magras ou com um corpo atlético, utilizando roupas e acessórios da moda. Constatamos também que a experiência de pesquisa através do filtro Tumblr se repete com outros termos, por exemplo: Casal + Tumblr; Leitura + Tumblr; Quarto + Tumblr, entre outros, conforme as figuras abaixo:

Figura 2 - Casal Tumblr

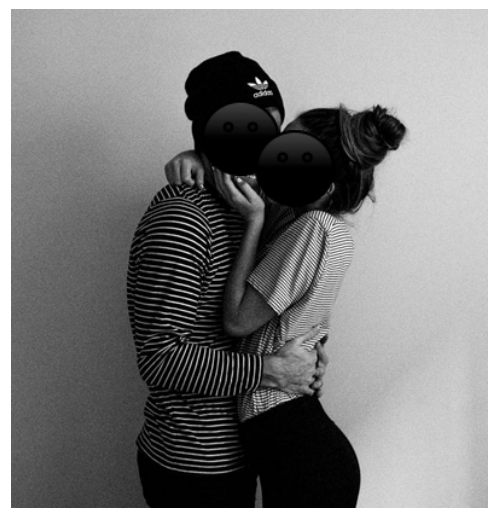

Figura 3 - Leitura Tumblr

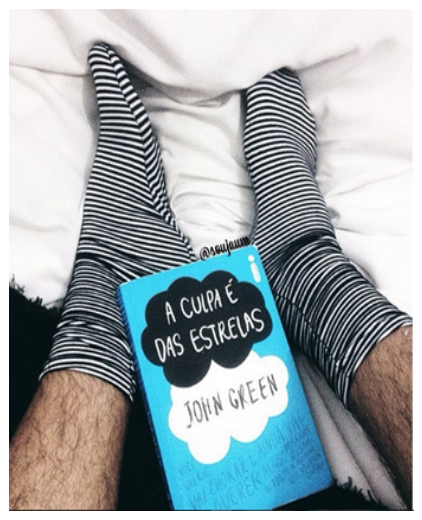

Figura 4 - Quarto Tumblr

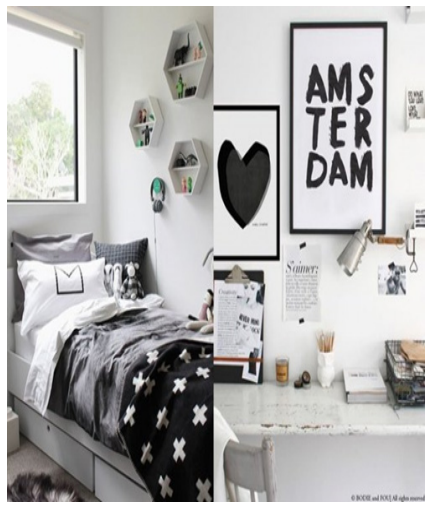

Fonte: Google imagens (2020).

Assim como na pesquisa anterior, os primeiros 66 resultados da pesquisa Casal + Tumblr exibem também casais caucasianos, atléticos, em locais paradisíacos e em casas bem decoradas. Os resultados correlatos aos termos Leitura + Tumblr apresentam citações de livros de romance, poesia, capas de best sellers, imagens de livros acompanhadas de outros objetos, como xícaras de café e óculos de leitura. Além disso, os filtros 
dessas imagens, em sua grande maioria, seguem um estilo retrô, com efeitos em sépia ou preto e branco. Os resultados para a pesquisa Quarto + Tumblr mostram residências luxuosas, com decorações minimalistas. Tais fotografias configuram-se como posicionamentos de usuários, pois há uma mobilização de várias semioses (estilo de escrita, poses, filtros, cenário, linguagem corporal, etc.) em diferentes contextos, para que os visualizadores identifiquem as características Tumblr e aprovem o resultado por meio do símbolo like. Ao mesmo tempo em que esses posicionamentos são constituídos pelo estilo Tumblr, eles reforçam a sua constituição, por meio da "escolha cuidadosa do vocabulário e outros recursos." (BARTON; LEE, 2015, p. 119).

Dadas essas considerações sobre o ato de se posicionar enquanto um usuário Tumblr e como é configurada a dinâmica neste universo, a seção a seguir retrata a metodologia que guiou a mineração e interpretação dos dados desta pesquisa.

\section{Metodologia}

Para a obtenção dos dados, registramos, no período de seis meses, o funcionamento, as regras e práticas de um canal no YouTube e da plataforma Tumblr, a fim de buscar dados que pudessem fundamentar a proposta deste estudo. Realizamos uma pesquisa qualitativa, parcialmente etnográfica no meio virtual, a partir de nossa experiência como seguidores do canal que elegemos para análise e usuários da plataforma Tumblr. Essa metodologia está fundamentada nos pressupostos de Hine (2000, p. 65) que explica que "a etnografia virtual é necessariamente parcial" "basear-se em ideias de relevância estratégica, e não em representações concretas de realidades objetivas" ${ }_{11}$.

Assim, esta pesquisa é parcialmente etnográfica porque nos limitamos a analisar uma plataforma virtual, um vídeo e as produções discursivas de cinco visualizadores deste vídeo no YouTube, não observando os percursos off-line de seus produtores/visualizadores nem realizando entrevistas com os participantes. A triangulação de dados foi feita entre as materialidades contidas nesses três espaços ${ }^{12}$. Ao descrever as limitações da etnografia virtual, Flick (2009) explica a necessidade de inclusão das conexões dos usuários da internet com o

\footnotetext{
10 "Virtual ethnography is necessarily partial."

11 "(...) be based on ideas of strategic relevance rather than faithful representations of objective reality."

${ }^{12}$ Plataformas YouTube e Tumblr e espaços de comentários no vídeo do YouTube.
} 
V. 11 (3)

$335-355$

set-dez

2021

mundo real ${ }^{13}$ e a dificuldade de se traçar essas conexões. No caso deste estudo, uma das dificuldades encontradas para a coleta de dados foi o encerramento temporário do canal do YouTube escolhido, pouco antes do início da coleta dos dados ${ }^{14}$.

Quanto à experiência dos participantes na tomada de posicionamento no contexto virtual, levamos em consideração o fato de que "o ciberespaço não deve ser pensado como um espaço separado de quaisquer conexões com a "vida real" e a interação face a face. Possui conexões ricas e complexas com os contextos onde acontecem" 15 (HINE, 2000, p. 64). Na mesma direção, Jones (2004) afirma que as interações virtuais não acontecem em um vácuo, ao contrário, estão fortemente imbricadas no mundo material. Analogamente, Orgad (2009, p. 37) reforça essa premissa quando advoga que "precisamos de dados offline para entender os fenômenos on-line $\mathrm{e}^{16 "}$.

A coleta de dados deu-se por meio de observação participante. A motivação surgiu de nossa identificação com o canal escolhido para análise do YouTube, o qual éramos seguidores/visualizadores e produtores de comentários, quando o vídeo e as fotos relacionadas ao Tumblr foram postados. Sobre a necessidade da experiência do etnógrafo no campo investigado para que haja uma compreensão mais abrangente do fenômeno, Hine (2000, p. 47) refere-se às considerações de Rosaldo (1989) para marcar a posição do pesquisador. A autora explica que "O etnógrafo não é simplesmente um voyeur ou um observador desapegado, mas também é, de certa forma, um participante, compartilhando algumas das preocupações, emoções e compromissos dos sujeitos da pesquisa" ${ }^{17}$. Deste modo, na posição de pesquisadores, no caso do Tumblr e de seguidores do Canal YouTube ${ }^{18}$, traçamos o seguinte percurso de investigação:

${ }^{13}$ Como pesquisadores de práticas na internet, consideramos contexto físico o que Flick (2009) chamou de mundo real.

${ }^{14}$ Constatamos, depois de ter finalizado a escrita deste artigo, que o canal foi reaberto.

15 "Cyberspace is not to be thought of as a space detached from any connections to 'real life' and face-to-face interaction. It has rich and complex connections with the contexts in which it is used."

16 "We need offline data to make sense of online phenomena."

17 "The ethnographer is not simply a voyeur or a disengaged observer, but is also to some extend a participant, sharing some of the concerns, emotions and commitments of the research subjects."

${ }^{18}$ Éramos seguidores do canal há cerca de quatro meses antes do vídeo selecionado para análise ser postado. Fizemos um levantamento dos comentários desde que nos tornamos seguidores e encontramos aproximadamente uma crítica em dez vídeos postados. 
1) Levantamento das regras oficiais, determinadas em duas páginas oficiais da plataforma Tumblr, em inglês e em português (seção 2 deste artigo);

2) Comparação das fotos produzidas a partir do vídeo sobre como produzir fotos para a plataforma Tumblr com fotos e regras estabelecidas pelos usuários do Tumblr (seção 2);

3) Análise do posicionamento de uma YouTuber, no seu canal no YouTube, especificamente no vídeo selecionado (seção 4.1);

4) Análise do posicionamento de cinco visualizadores deste vídeo, por meio de suas produções discursivas, no espaço reservado para comentários no YouTube (seção 4.2).

Para a abordagem dos dados, concebemos a internet como artefato cultural, isto é, "um produto da cultura: uma tecnologia que foi produzida por pessoas particulares com objetivos e prioridades situadas contextualmente."19 (HINE, 2000, p. 9). Enfatizamos, nessa perspectiva, os vários usos e apropriações que os usuários fazem da internet, concebendo-a como um artefato com significados culturais diversos (FRAGOSO; RECUERO; AMARAL, 2011, p. 42). Na análise do vídeo, analisamos a prática da postagem de uma YouTuber, tendo as características do Tumblr como referência e as propiciações da Web 2.0, cujas interfaces permitem a manifestação de práticas não isoladas, mas ao contrário, potencialmente conectadas (BOLANDER; LOCHER, 2020). Detalhamos na análise dos dados, a seguir, os procedimentos apresentados nesta seção.

\section{Análise dos dados}

Iniciamos esta seção, apresentando brevemente o canal do Youtube selecionado para análise, seguido do posicionamento da YouTuber nesse canal, a fim de contextualizar seu caminho até a postagem do vídeo que ensina a fazer fotos para a plataforma Tumblr. Na segunda parte, analisamos a postura dos usuários/visualizadores, por meio da análise de seus comentários.

O canal é um espaço dedicado às postagens sobre a vida de uma jovem que mora no campo, em uma cidade no interior da região do

19 "a product of culture: a technology that was produced by particular people with contextually situated goals and priorities." 
V. 11 (3)

$335-355$

set-dez

2021

nordeste do Brasil. A YouTuber mostra, para cerca de 794 mil20 inscritos, cenas de sua rotina relacionada à terra, aos animais, à culinária e ao seu contexto local. No vídeo selecionado, a YouTuber fotografa-se destacando o cenário e apresenta dicas de como produzir fotos no estilo Tumblr, conforme discorremos adiante.

\section{Posicionamento da YouTuber: leituras de formas contemporâneas de se expressar}

Diferente de muitos vídeos no YouTube, com produção especializada ${ }^{21}$, a YouTuber do canal selecionado mostra como é a sua vida no campo, através de imagens sem efeitos especiais ou filtros, registradas por meio de um smartphone. Em seus vídeos, ela geralmente não usa maquiagem e apresenta-se sempre com camiseta, saia e sapato baixo. Esse é o posicionamento que escolhe para se representar no canal: multimodalmente, narra e mostra imagens da roça, serras, animais e comidas típicas. O logotipo do seu canal é composto por elementos regionais relacionados à cultura nordestina, como o cacto e o chapéu de cangaceiro.

Dentre os muitos vídeos postados, escolhemos para análise, um vídeo que sugere modos de criar fotos para outra plataforma e os cinco primeiros comentários sobre ele ${ }^{22}$, pois identificamos nesse material, posicionamentos adversos, gerados a partir da visualização das imagens apresentadas no conteúdo geral do canal ${ }^{23}$. Com a ajuda de sua irmã, neste vídeo, a YouTuber teve como objetivo criar um tutorial de fotos seguindo o estilo Tumblr. O cenário escolhido foi o espaço da zona rural, em um dia chuvoso. Nas imagens, são retratados elementos constitutivos da vida campesina, por exemplo, o verde das plantações, cercas, frutas, etc.

Embora a escolha do local fosse propícia para a criação de fotos seguindo o estilo Tumblr24, a combinação das linguagens adotadas

\footnotetext{
${ }^{20}$ Número correspondente ao número de inscritos até o dia 20/07/2020.

${ }^{21} \mathrm{O}$ canal que analisamos não era monetizado na época de produção do vídeo.

${ }^{22}$ Lançado em 12/04/2018, atualmente o vídeo tem 8.527 comentários, 64 mil curtidas e 4,2 mil dislikes. A maioria dos comentários e curtidas são positivos. Entretanto, optamos por analisar o posicionamento que reflete $6,56 \%$ dos usuários, os quais fizeram críticas à postagem.
}

23 Antes da postagem do vídeo analisado neste estudo, éramos seguidores do canal e acompanhávamos os vídeos e comentários. A YouTuber recebia elogios e pedidos de temas para serem inclusos nas postagens. Eram raras as críticas ao conteúdo do canal, por isso, a reação dos visualizadores no episódio do Tumblr nos chamou a atenção.

${ }^{24}$ Propícia, segundo as orientações oficiais contidas na página oficial da plataforma. 
pela YouTuber parece não ter convencido 6,77\%, ou seja, 4.200 dos visualizadores que desaprovaram a produção com um sinal de dislike e comentários cujas críticas apontam para a não identificação de tal estilo nas semioses produzidas pelo vídeo e pelas fotos.

Aplicando as três categorias de ação sobre posicionamento, de acordo com Harré e Slocum (2003), inferimos que a produção da YouTuber pode ter sido incentivada pela reação normalmente positiva de seguidores que continuamente elogiavam suas postagens e sugeriam a postagem de novos temas; pode também ter sido incentivada pela mensagem oficial da plataforma: "Tudo cabe nos 497 milhões de blogs que compõem o Tumblr".

Quanto à desaprovação dos 6,77 \% de visualizadores, sugerimos que a construção discursiva multimodal que alicerça a plataforma, e ao mesmo tempo é alicerçada pelos seus seguidores, provocou uma ruptura de expectativas na combinação das múltiplas linguagens adotadas pela YouTuber, que não correspondeu ao padrão ser Tumblr. Essa premissa está baseada nos primeiros 55 resultados da pesquisa fotos + Tumblr (Figura 1), que exibiu somente imagens de mulheres caucasianas, magras ou com um corpo atlético, utilizando roupas e acessórios da moda.

A desaprovação das fotos no vídeo da YouTuber sinaliza a existência da pressão de um grupo para o uso de uma norma da língua(gem) on-line, bem como posicionamentos guiados por uma assimetria de "prestígios discursivos e linguísticos de grupos de pessoas." (FAIRCLOUGH, 2001, p. 25).

Vejamos o resultado de uma das fotos produzidas pela YouTuber:

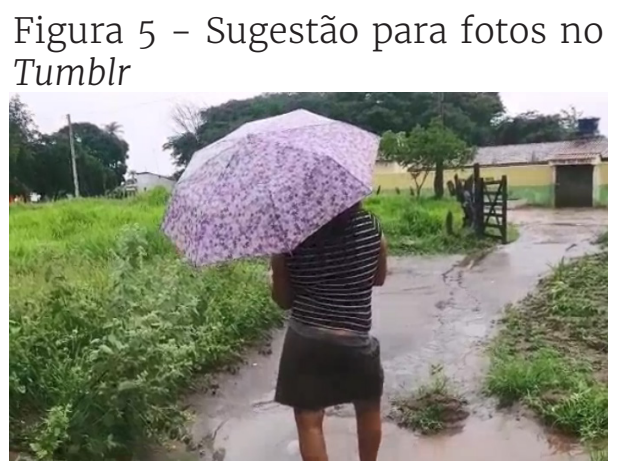

Fonte: Youtube (2020).

A Figura 5 é fruto do vídeo no qual ela oferece o tutorial de fotografia estilo Tumblr. Exceto pela falta de filtro, a foto segue as proposições utilizadas pelos usuários do site: o uso de luz natural, cores 
v. 11 (3)

$335-355$ set-dez 2021

minimalistas na roupa (camiseta listrada e saia cinza) e a escolha de um ângulo diferenciado para fotografar. No vídeo que antecede a tomada das fotos, após a finalização da primeira fotografia (Figura 5), a irmã da YouTuber interage, ao mesmo tempo, com ela e com os visualizadores do vídeo/fotos, conforme o excerto abaixo:

Excerto 1: [...] Vira a sombrinha pra cá. Abaixa para trás! Pronto! [...] Confiram a foto para ver se vocês gostaram. [Irmã].

Para compreender o posicionamento nas interações, Harré (2012) propõe a análise do modo como as pessoas negociam ou ganham acesso aos direitos para agir em situações específicas. No Excerto 1, essa negociação acontece na interação simultânea entre produtora e YouTuber e produtora e visualizadores da foto. Neste movimento, chama a atenção dos visualizadores, quando interage com a YouTuber, por meio dos imperativos "vire a sombrinha pra cá e abaixa para trás", para a existência das normas do padrão Tumblr, citadas por Mingo. Cabe ressaltar que a Figura 5 assemelha-se aos resultados do Google Imagem, para a pesquisa: Fotos + Tumblr + Guarda-chuva, conforme os exemplos a seguir:

Figura 6

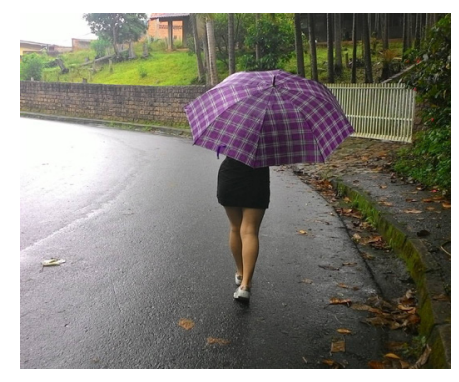

Fonte: https://bit.ly/3fLgloa
Figura 7

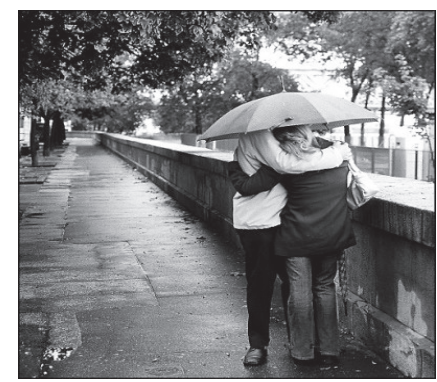

Fonte: https://bit.ly/2zsFti3
Figura 8

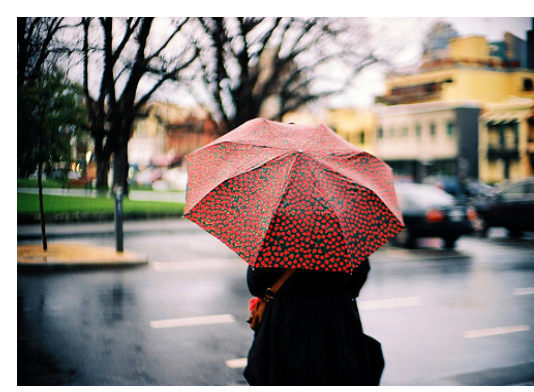

Fonte: https://bit.ly/2WsHlBr

Adiante, podemos observar mais elementos do campo nas fotos Tumblr da YouTuber, tais como a mata, as árvores e a horta. Esses elementos fazem parte do seu posicionamento enquanto uma criadora de material digital. 
Figura 9 - Foto Tumblr na chuva

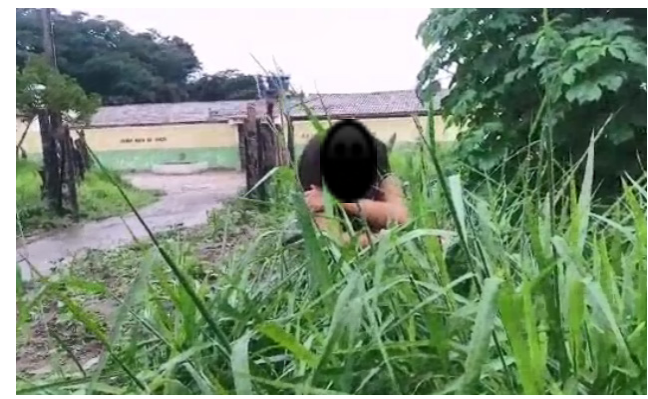

Figura 10 - Foto Tumblr na horta

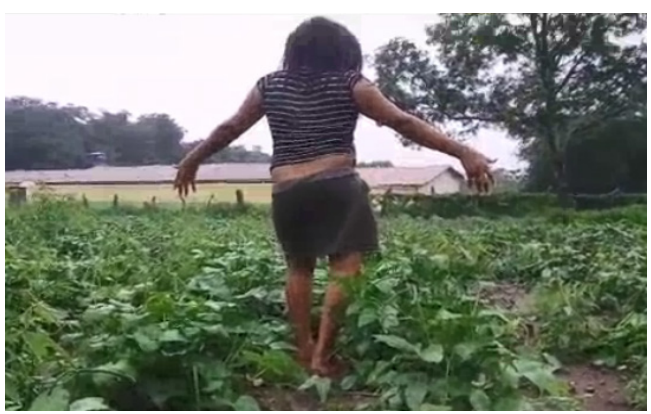

Fonte: YouTube (2020).

Mesmo assim, para 4.200 usuários, tal posicionamento não foi considerado Tumblr. A falta de uma justificativa faz-nos inferir que a YouTuber não teria características estabelecidas para posicionar-se deste modo, segundo alguns usuários, pois, do contrário haveria ao menos uma prescrição explícita, informando o motivo das críticas. De qualquer modo, entendemos que o posicionamento da YouTuber, a partir de uma leitura do estilo Tumblr, foi um ato que rompeu com leituras padronizadas de comportamento e estilos e que foi estimulado pela popularidade do seu canal. Nessa perspectiva, podemos dizer que os atos de posicionamento nas plataformas digitais e nos espaços de interação representam maneiras de criar, dar e se apropriar de significados e, ao mesmo tempo, ressignificá-los em espaços particulares de interpretação do macro, disponível na rede.

\section{Posicionamento dos visualizadores do vídeo no ato de comentar: prescrições e rupturas}

Os símbolos curti/ não curti/ amei estão disponíveis no YouTube para a ressemiotização dos enunciados (IEDEMA, 2001), e também podem ser expressos na escrita, no espaço reservado para comentários. Os comentários dos usuários representados nas figuras 11, 12 e 13 revelam desaprovação do vídeo, conforme reproduzimos a seguir:

Figura 11 - Usuário 1

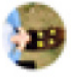

Mose RAude knoses 3 weeks ago Tumblim?

1. 1 \& REPLY

Fonte: YouTube (2020).
Figura 12 - Usuário 2

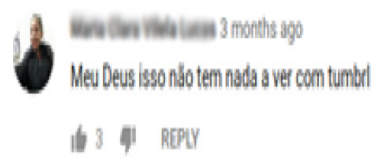

Fonte: YouTube (2020).
Figura 13 - Usuário 3

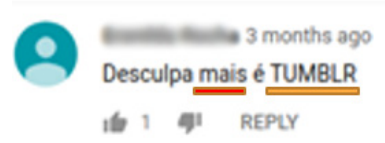

Fonte: YouTube (2020). 
V. 11 (3)

$335-355$ set-dez 2021

Consideramos que as posturas dos usuários 1 e 2 são alimentadas por questões ideológicas e de pertencimento, que funcionam como críticas à construção multissemiótica da YouTuber do que é ser Tumblr. O questionamento do Usuário 1 é atravessado por um discurso normativo, que repreende o vídeo por meio da repetição dos pontos de interrogação. Sob este aspecto, Cunha e Cintra (2002) explicam que os sinais de entoação ou melodia buscam reproduzir o tom e a intenção do enunciado. Desse modo, a combinação de dois ou de mais sinais tem como objetivo transparecer o volume da voz e o sentir do sujeito que enuncia. Interpretamos o posicionamento do Usuário 1 como o de um protetor das normas criadas por um grupo de usuários do Tumblr, sem considerar os significados do vídeo que, segundo nossa análise, têm outro sentido no canal da YouTuber. O aspecto semântico da comunicação, neste caso, fica comprometido, porque o posicionamento do Usuário 1 representa uma força centrífuga, cujo objetivo é controlar os sentidos do vídeo.

Seguindo esse caminho, o Usuário 2 se posiciona por meio de uma locução interjetiva: "Meu Deus[...]", exprimindo, desse modo, uma ideia de espanto, descontento, uma vez que, segundo seu entendimento, as fotografias "[...] não tem nada a ver com Tumblr". Assim como acontece no primeiro exemplo, o Usuário 2 desconsidera a leitura da YouTuber do que são fotos Tumblr, desqualificando este posicionamento por não atender aos requisitos esperados por ele. Há em tal posicionamento uma leitura conceitual do eu [usuário do Tumblr] que se nega no outro [YouTuber]. Em outras palavras, o posicionamento do Usuário 2 sugere que para produzir o efeito Tumblr, a convergência da produção nas duas plataformas deveria seguir um padrão pré-estabelecido, mas que ele não informa qual é. Com isso, do mesmo modo que o posicionamento do exemplo anterior, este usuário parece querer controlar/estabelecer os sentidos do estilo Tumblr.

Reescrevendo em caixa alta o termo TUMBLR, o Usuário 3 destaca a grafia incorreta, escrita com e - Tumbler - pela YouTuber, no título do vídeo. Associamos esse posicionamento ao equivalente à função que tem o dicionário na manutenção da escrita considerada correta das palavras. O Usuário 3 ressalta sua posição de vigilante da escrita mostrando, desse modo, seu conhecimento sobre esta comunidade. Ignora, no entanto, a diferença entre a grafia da conjunção adversativa mas e do advérbio de intensidade mais. Embora tal inadequação seja aceita na escrita virtual, pela espontaneidade, informalidade e agilidade 
característica do internetês (MARCUSCHI; DIONÍSIO, 2007), é curioso o seu uso justamente em um enunciado que repreende a grafia incorreta do termo Tumblr, uma construção que não gera dúvidas sobre o referente.

Sobre o uso da caixa alta no mesmo comentário - TUMBLR -, Barton e Lee (2015, p. 119) explicam que palavras e expressões escritas deste modo, na interação on-line, "representa[m] um grito e um tipo de comportamento flaming, ou seja, uma linguagem ofensiva e agressiva". O que está implícito neste comentário é que se a pessoa não sabe escrever a palavra corretamente, ela não pertence ao grupo. Este é um aspecto interessante de se observar na interação on-line, pois conforme Barton e Lee (2015), na compreensão da linguagem no meio virtual, é profícuo entender como os modos diferentes de linguagem trabalham juntos para formar textos on-line coerentes e dotados de sentido.

Um caminho diferente foi tomado pelos Usuários 4 e 5, a seguir. Além dos posicionamentos contrários às fotografias que reivindicam o estilo Tumblr, tais usuários se posicionaram em defesa da YouTuber:

Figura 14 - Usuário 4

Q Isso eque e fumblt, pessoa de VERDADE. Näo essas meninas querendo ter uma vida de MENTIRA 1. 42 \& REPQY

Fonte: YouTube (2020).
Figura 14 - Usuário 5

NOSSA BEM MELLOR QUE AQUELAS BOLGUEIRINHAS, esse lugar deve trazer uma paz imensa (16) 55 if REPLY

Fonte: YouTube (2020).

Além do número elevado de curtidas no comentário do Usuário 4, chama a atenção o fato dos Usuários 4 e 5 terem conhecimento do estilo Tumblr que é trazido à tona nas entrelinhas dos comentários anteriores. Entretanto, diferente de tais comentários, os internautas se posicionaram criticamente sobre esse estilo, reforçando que as características do vídeo não os contemplam. Fazem esse movimento exaltando o posicionamento da YouTuber, "uma pessoa de VERDADE", provavelmente referindo-se à produção caseira das fotos, em contraste com "a vida de MENTIRA" que o Usuário 4 vê como objeto de desejo das meninas com perfil na plataforma Tumblr. As palavras verdade e mentira são grafadas em caixa alta para realçar o contraste entre a produção da YouTuber e as produções oficiais do Tumblr. O posicionamento da YouTuber, neste caso, é o real, alcançável ao passo que o celebrado posicionamento das meninas do Tumblr classifica-se, segundo o Usuário 4, no nível de um desejo, de uma ilusão. Sobre essa 
V. 11 (3)

$335-355$

set-dez

2021

constatação, Jenkins (2009) destaca a importância da reformulação de sentido que acontece dentro da cultura do YouTube. No caso do comentário analisado, trata-se de uma reformulação desvinculada da prática no Tumblr, pois é expressa em outro contexto e plataforma. A capacidade de compreender a inter-relação entre contexto, público e identidade é, de acordo com boyd (2014), um dos principais desafios no trânsito das redes sociais.

O comentário do Usuário 5, traz uma interjeição de surpresa inicial ("NOSSA") para, então, comparar o vídeo da YouTuber às fotos tradicionais da plataforma do Tumblr. Para isso, usa um grau de comparativo de superioridade e em caixa alta para exaltar a produção da YouTuber e refere-se às meninas Tumblr com um adjetivo na forma diminutiva. O pronome demonstrativo aquelas remete ao contexto distante em que se encontram as outras produsuárias, indicando, assim, tanto a consciência da reformulação de sentidos de um contexto para o outro, quanto o trânsito entre as redes sociais, conforme as ponderações de Jenkins (2009) e boyd (2014). Marca, também, uma crítica ao posicionamento dos produsuários do universo Tumblr e seus seguidores.

\section{Considerações finais}

Neste estudo, observamos que o posicionamento de uma YouTuber na produção do vídeo com dicas de postagem no Tumblr está alinhado ao conceito do novo ethos associado aos novos letramentos, com regras e normas mais fluidas (LANKSHEAR; KNOBEL, 2007). Ao atravessar duas plataformas e postar conteúdo em seu próprio canal, a YouTuber realizou o objetivo de apresentar-se de acordo com a sua leitura de determinado estilo prevendo, possivelmente, uma reação positiva de seus seguidores. Concluímos que os posicionamentos observados nos comentários sobre o vídeo estão relacionados às questões ideológicas, socioculturais, identitárias e de pertencimento de usuários que transitam entre as espacialidades físicas e digitais, alguns deles tentando blindar práticas e comportamentos em espaços virtuais de interação. O tipo de posicionamento dos Usuários 1, 2 e 3 sugere a filiação a um discurso intolerante, replicado no meio digital, conforme esperado, marcando uma vigilância em prol de padrões preestabelecidos de conduta. Sobre este assunto, Leander e Mckin (2003) esclarecem que os perfis nas redes sociais representam o usuário em sua totalidade, 
não havendo, deste modo, uma separação do mundo físico e do digital. Outras condições contextuais devem sim ser consideradas como, por exemplo, os interlocutores envolvidos, os objetivos da interação e as atividades e redes sociais que os usuários participam tanto em um contexto quanto em outro.

Em resposta aos comentários negativos e posicionando-se em tom solidário à YouTuber, o usuário 4 afirmou que não se tratava do estilo Tumblr, mas de algo mais verdadeiro, em oposição à mentira que, segundo ele, marca as produções Tumblr. Tal comentário aponta para o desenvolvimento de um posicionamento crítico em relação a certos padrões e práticas preestabelecidos e, portanto, de interesse para os estudos linguísticos e sociais ${ }^{25}$, por incentivar a manifestação de identidades, sem que outras identidades e posicionamentos sejam desrespeitados e, de certo modo, ampliar as possibilidades de se "pensar a vida social ou nossas identidades sociais descontextualizadamente", conforme advogam Fabrício e Moita Lopes (2002, p. 13).

Concluímos, a partir dessa discussão, que as redes sociais representam espaços de representatividade identitária, divergência de ideias e posicionamentos distintos, que são expressos por meio das múltiplas linguagens propiciadas nessa espacialidade. A participação dos usuários nas práticas sociais e de linguagem no contexto digital das redes sociais possibilita e favorece a construção e ressignificação de sentidos, por meio das possibilidades de interação disponíveis e favorecem a experimentação de identidades. Demarcam, deste modo, a heterogeneidade de cada usuário, seja nos comentários, compartilhamentos de conteúdos, postagens, ou pela sinalização dos símbolos disponíveis para expressão. Esses posicionamentos ampliam o compartilhamento de pontos de vista e, assim, de possibilidades de criatividade, reflexão e criticidade dos usuários no fluxo nos/dos meios on e off-line.

\section{Referências}

BARTON, D.; LEE, C. Linguagem online: textos e práticas digitais. Tradução de Milton C. Mota. 1a . ed. São Paulo: Parábola editorial, 2015. 270p.

BOLANDER, B.; LOCHER, M. A. Beyond the online offline distinction: entry points to digital discourses. Discourse, Context \& Media. V. 35, 2020. https://doi.org/10.1016/j.dcm.2020.100383. Disponível em: https://www. sciencedirect.com/science/article/abs/pii/S2211695820300167. Acesso em: 12 mai. 2020.

${ }^{25} \mathrm{Na}$ perspectiva que discutimos neste artigo. 
V. 11 (3) $335-355$ set-dez 2021
BOYD, d. It's complicated: the social lives of networked teens. New Haven and London: Yale University Press, 2014. 296p.

BOYD, d. Why youth (heart) social network sites: the role of networked publics in teenage social life. In: BUCKINGHAM, D. (Ed.). MacArthur Foundation Series on Digital Learning: youth, identity, and digital media volume. Cambridge, MA: MIT Press, 2007, p. 119-142.

BRUNS, A. The future is user-led: the path towards widespread produsage. Fibreculture Journal, v. 11, 2008. Disponível em: http://journal.fibreculture. org/ Acesso em: 08 jul. 2019.

COSCARELLI, C. V. (Org.). Tecnologias para aprender. $1^{\mathrm{a}}$. ed. São Paulo: Parábola Editorial, 2016. 192p.

CUNHA, C.; CINTRA, L. Nova gramática do português contemporâneo. Rio de Janeiro: Nova Fronteira, 2002. 795p.

DAVIES, B.; HARRÉ, R. Positioning: The discursive production of selves. Journal for the Theory of Social Behaviour, v. 20, n. 1, p. 43-63, 1990.

DAVIES, B.; HARRÉ, R. Positioning and personhood. In: HARRÉ, R.; VAN LANGENHOVE, L. (Eds.). Positioning theory. Oxford: Wiley-Blackwell, 1999, p. $32-52$.

DIONÍSIO, A. P. Gêneros multimodais e letramento. In: KARWOSKI, A. M. GAYDECZKA, B.; BRITO, K. S. (Orgs.). Gêneros textuais: reflexões e ensino. $2^{\mathrm{a}}$. ed. Rio de Janeiro: Lucerna, 2006, p. 137-151.

FABRÍCIO, B. F.; MOITA LOPES, L. P. Discursos e vertigens: identidades em xeque em narrativas contemporâneas. Revista de Estudos Linguísticos, Juiz de Fora, v. 6, n. 02, p. 11-29, 2002.

FAIRCLOUGH, N. Language and power. $2^{\text {nd }}$. ed. London: Longman, 2001. 274p.

FLICK, U. Introdução à pesquisa qualitativa. $3^{\mathrm{a}}$. ed. Tradução de Joice Elias Costa. Porto Alegre: Artmed, 2009. 405p.

FRAGOSO, S.; RECUERO, R.; AMARAL, A. Métodos de pesquisa para internet. Porto Alegre: Sulina, 2011. 239p.

HALLIDAY, M. A. K.; MATTHIESSEN, C. An introduction to functional grammar. $3^{\text {rd }}$. ed. London: Hodder Arnold, 2004. 700p.

HARRÉ, R. Positioning theory: Moral dimensions of social-cultural psychology. In: VALSINER, J. (Ed.). The Oxford handbook of culture and psychology. New York: Oxford University, 2012, p. 191-206.

HARRÉ, R.; SLOCUM, N. Disputes as complex social events: On the uses of positioning theory. In: HARRÉ, R.; MOGHADDAM, F. (Eds.). The self and others: positioning individuals and groups in personal, political, and cultural contexts. London: Praeger, 2003, p. 123-136.

HINE, C. Virtual Ethnography. London: SAGE Publications, 2000. 192p. 
IEDEMA, R. Multimodality, resemiotization: extending the analysis of discourse as multi-semiotic practice. Visual communication, v. 2, n. 1, p. 29-57, 2003.

JENKINS, H. Cultura de convergência. Tradução de Susana L. de Alexandria. $2^{\mathrm{a}}$ ed. São Paulo, Aleph, 2009. 428p.

JONES, R. H. The problem of context in computer mediated communication. In: LEVINE, P.; SCOLLON, R. (Eds.). Discourse and Technology: multimodal discourse analysis. Washington, D.C.: Georgetown University Press, 2004, p. $20-33$.

KAYI-AYDAR, H. Positioning theory in Applied Linguistics: research design and applications. Cham, SIW: Palgrave Macmillan, 2019. 214p.

LANGENHOVE, V.; HARRÉ, R. Introducing Positioning theory. In: HARRÉ, R.; LANGENHOVE, L. V. (Eds.). Positioning theory. Oxford: Blackwell, 1999, p. $14-31$.

LANKSHEAR, C.; KNOBEL, M. Sampling "the New" in new literacies. In: KNOBEL, M.; LANKSHEAR, C. (Eds.). A new literacies sampler. New York: Peter Lang, 2007, p. 01-24.

LEANDER, K. M.; MCKIM, K. Tracing the everyday 'sitings' of adolescents on the internet. Education, communication and information, v. 3, n. 1, p. 11-30, 2003.

MARCUSCHI, L. A.; DIONÍSIO, A. P. (Orgs.). Fala e escrita. Belo Horizonte: Autêntica, 2007, p. 31-55.

MARTINS, E., C.; SANTOS, G. L. O desenvolvimento da capacidade de argumentação em mídias sociais digitais: o uso pedagógico do WhatsApp. ETD: Educação Temática Digital. Campinas, SP, v. 20, n.1, p. 137-152, 2018.

MiNGO, M. O que é estilo Tumblr? Tudo sobre essa tendência da internet. Superela, 14 nov. 2017. Disponível em: https://superela.com/o-que-e-estilotumblr-tudo-sobre-essa-tendencia-da-internet/ Acesso em: 18 abr. 2019.

O'REILLY, T. What is Web 2.0: designing patterns and business models for the next generation of softwares. In: O'Reilly, T. Spreading the knowledge of innovators, 2005. Disponível em: http://oreilly.com/web2/archive/what-isweb-20.html. Acesso em: 07 abr. 2019.

ORGAD, S. How can researchers make sense of the issues involved in collecting and interpreting online and offline data? In: MARKHAM, A; BAYM N. (Eds.). Internet Inquiry: Conversations about Methods. Thousand Oaks, California: Sage, 2009, p. 33-53.

SLOCUM, N.; LANGENHOVE, V. Integration speak: Introducing positioning theory in regional integration studies. In: HARRE, R.; MOGHADDAM, F. (Eds.). The self and others: Positioning individuals and groups in personal, political, and cultural contexts. London: Praeger, 2003, p. 219-235.

ZACHARIAS, V. R. C. Letramento digital: desafios e possibilidades para o ensino. In: COSCARELLI, C. V (Org.). Tecnologias para aprender. $1^{\mathrm{a}}$. ed. São Paulo: Parábola Editorial, 2016, p. 15-26. 